\title{
Higher dietary salt intake is associated with microalbuminuria, but not with retinopathy in individuals with type 1 diabetes: the EURODIAB Prospective Complications Study
}

\author{
Lian Engelen • Sabita S. Soedamah-Muthu • Johanna M. Geleijnse • \\ Monika Toeller • Nish Chaturvedi • John H. Fuller • \\ Casper G. Schalkwijk • Coen D. A. Stehouwer
}

Received: 7 July 2014 / Accepted: 5 August 2014 / Published online: 30 August 2014

(C) The Author(s) 2014. This article is published with open access at Springerlink.com

\begin{abstract}
Aims/hypothesis High dietary salt intake has been associated with elevated BP and may also have a deleterious effect on microvascular complications. We studied the cross-sectional associations between dietary salt intake (estimated from $24 \mathrm{~h}$ urinary sodium excretion) and urinary potassium excretion on the one hand, and the prevalence of microvascular complications on the other, in individuals with type 1 diabetes.
\end{abstract}

Electronic supplementary material The online version of this article (doi:10.1007/s00125-014-3367-9) contains peer-reviewed but unedited supplementary material, which is available to authorised users.

L. Engelen $(\bowtie) \cdot$ C. G. Schalkwijk · C. D. A. Stehouwer Department of Internal Medicine, Maastricht University Medical Centre, Universiteitssingel 50, 6200 MD Maastricht, the Netherlands e-mail: l.engelen@maastrichtuniversity.nl

L. Engelen • C. G. Schalkwijk · C. D. A. Stehouwer CARIM School for Cardiovascular Diseases, Maastricht University Medical Centre, Maastricht, the Netherlands

L. Engelen · J. M. Geleijnse • C. G. Schalkwijk • C. D. A. Stehouwer Top Institute Food and Nutrition, Wageningen, the Netherlands

S. S. Soedamah-Muthu $\cdot$ J. M. Geleijnse

Division of Human Nutrition, Wageningen University, Wageningen, The Netherlands

M. Toeller

Heinrich-Heine-University Düsseldorf, Düsseldorf, Germany

N. Chaturvedi

International Centre for Circulatory Health, National Heart and Lung Institute, Imperial College London, London, UK

\section{J. H. Fuller}

Department of Epidemiology and Public Health, Royal Free and University College London Medical School, London, UK
Methods We measured sodium and potassium concentrations in two $24 \mathrm{~h}$ urine samples in 1,212 individuals with type 1 diabetes ( $40 \pm 10$ years old, $51 \%$ men) who participated in the EURODIAB Prospective Complications Study. We used multiple logistic regression analyses to investigate associations between dietary salt intake and microvascular complications adjusted for age and sex, and additionally for BMI, smoking, urinary potassium excretion, antihypertensive medication and physical activity, and total energy, protein, alcohol, saturated fat and fibre intake.

Results After full adjustment, $1 \mathrm{~g} /$ day higher dietary salt intake was positively associated with the presence of microalbuminuria (OR 1.06 [95\% CI 1.01, 1.10]), but not macroalbuminuria (OR 0.99 [95\% CI 0.94, 1.05]), nonproliferative retinopathy (OR $1.00(95 \%$ CI $0.96,1.04])$ or proliferative retinopathy (OR $1.02(95 \%$ CI $0.95,1.08])$. After excluding individuals with cardiovascular disease and/or antihypertensive medication $(n=418)$, we found a nonsignificant association with microalbuminuria (OR 1.04 $[95 \%$ CI $0.99,1.10])$ and macroalbuminuria (OR 1.05 [95\% CI $0.96,1.16])$. The association between dietary salt intake and microalbuminuria was stronger in individuals with a BMI above $25 \mathrm{~kg} / \mathrm{m}^{2}$ (OR 1.11 [95\% CI 1.04, 1.18]) than in those with BMI below $25 \mathrm{~kg} / \mathrm{m}^{2}$ (OR 1.03 [95\% CI 0.97, 1.09]). No significant associations were found between urinary potassium excretion and microvascular complications.

Conclusions/interpretation In individuals with type 1 diabetes, higher dietary salt intake, as determined by $24 \mathrm{~h}$ urinary sodium excretion, may be positively associated with microalbuminuria, particularly in overweight individuals.

Keywords Albuminuria - Dietary salt intake .

Microvascular complications - Potassium excretion .

Retinopathy S Sodium excretion . Type 1 diabetes 


$\begin{array}{ll}\text { Abbreviations } \\ \text { CKD-EPI } & \begin{array}{l}\text { Chronic Kidney Disease Epidemiology } \\ \text { Collaboration }\end{array} \\ \text { CVD } & \text { Cardiovascular disease } \\ \text { FFQ } & \text { Food frequency questionnaire } \\ \text { MET-h } & \text { Weekly metabolic equivalent } \\ \text { RERI } & \text { Relative excess risk due to interaction }\end{array}$

\section{Introduction}

Nutritional advice is important in preventing or slowing the rate of development of diabetes-related cardiovascular disease (CVD). Nutritional advice that favourably affects cardiovascular risk factors, such as BP, may also have a favourable effect on microvascular complications such as retinopathy and nephropathy $[1,2]$. Lowering dietary salt intake is known to reduce $\mathrm{BP}[3]$.

Several large cohort studies conducted in the general population have investigated associations between dietary salt intake and prevalent microalbuminuria. In these studies dietary salt intake was estimated using either $24 \mathrm{~h}$ urinary sodium excretion [4-6], which is currently regarded as the reference method, or food frequency questionnaire (FFQ) [7, 8]. Both null $[4,8]$ and positive [5-7, 9] associations have been found between dietary salt intake and prevalent microalbuminuria in the general population.

In contrast, a smaller study on 270 individuals with type 2 diabetes in which a spot urine sample was used to estimate daily salt intake showed a 'J-shaped' association with albuminuria [10]. A J-shaped association was also found between $24 \mathrm{~h}$ urinary sodium excretion and all-cause mortality in individuals with type 1 diabetes [11]. In this Finnish cohort, low sodium excretion (the 10th percentile of the population) was also associated with the development of end-stage renal disease [11]. The association between dietary salt intake and (early) microvascular complications in individuals with type 1 diabetes, however, has not yet been established, except for one prospective study [12]. This study showed that in 469 AfricanAmerican patients with type 1 diabetes a high dietary sodium intake was associated with a higher 6 year incidence of macular oedema [12]. However, the authors used an FFQ to estimate dietary salt intake and potassium intake was not taken into account. High potassium intake has been shown to exert an inhibitory effect on sodium sensitivity [13] and high sodium intake in combination with low potassium intake results in further increases in BP [13]. However, the association between potassium intake and microvascular complications in type 1 diabetes has not yet been established.

We investigated the associations between sodium and potassium intake, estimated from $24 \mathrm{~h}$ urine samples, and the prevalence of microalbuminuria, macroalbuminuria, and non-proliferative and proliferative retinopathy in a European cohort of individuals with type 1 diabetes.

\section{Methods}

Study population We used data from the EURODIAB Prospective Complications Study, a European based prospective cohort study that has been described in detail elsewhere $[14,15]$. In brief, baseline investigations were performed between 1989 and 1991 on 3,250 patients with type 1 diabetes, defined as clinical diagnosis made before the age of 36 years, and needing continuous insulin therapy within 1 year of diagnosis. Patients aged 15-60 years were recruited from 31 centres in 16 European countries. Sample selection was stratified by sex, age group and duration of diabetes to ensure sufficient representation in all categories. These patients were invited for a follow-up examination on average 7-9 years after the baseline examinations. Of the 3,250 included patients, $1,880(57.8 \%)$ returned for re-examination. We performed cross-sectional analyses on these follow-up data (as urine samples of the baseline investigations were no longer available).

Ethics committee approval conforming to the Declaration of Helsinki was obtained at each centre and all participants provided written informed consent.

Urinary sodium and potassium excretion We measured urinary sodium and potassium concentrations in one $(n=119)$ or two $(n=1,093) 24 \mathrm{~h}$ urine samples of 1,212 individuals from the EURODIAB follow-up measurement in 1997 by means of an ion-selective electrode (Cobas 6000; Roche Diagnostics, Tokyo, Japan). We multiplied $24 \mathrm{~h}$ urinary sodium excretion (in $\mathrm{g} /$ day) by 2.5 to estimate the dietary salt intake (in $\mathrm{g} /$ day).

Microvascular complications The AER was measured from duplicate $24 \mathrm{~h}$ urine collections using an immunoturbidimetric method that included goat anti-human albumin antisera (Sanofi Diagnostics Pasteur, Chaska, MN, USA) and human serum albumin standards (ORHA 20/21 grade HSA; Behring Diagnostics, Hoechst UK, Hounslow, UK) [16]. Microalbuminuria and macroalbuminuria were defined as AER $20-200 \mu \mathrm{g} / \mathrm{min}$ and $>200 \mu \mathrm{g} / \mathrm{min}$, respectively. The GFR was estimated using the Chronic Kidney Disease Epidemiology Collaboration (CKD-EPI) equation [17].

Retinopathy was centrally assessed from retinal photographs by a trained reader of colour retinal photographs using a system of $45^{\circ}$ field grading standards for the assessment of retinopathy that was developed for the EURODIAB Prospective Complications Study. Non-proliferative retinopathy was defined as the presence of one or more microaneurysms, haemorrhages and/or hard exudates. Proliferative retinopathy was defined as any new vessel, 
fibrous proliferations, pre-retinal haemorrhage, vitreous haemorrhage or photocoagulation scar [18].

Covariables Weight and height were measured with indoor clothing without shoes and BMI was calculated as weight divided by height squared. Smoking habits were ascertained by questionnaire and individuals were categorised into never smokers, ex-smokers and current smokers. Self-reported physical activity was assessed by a questionnaire. The weekly metabolic equivalent (MET-h) corresponds to the weekly amount of time spent in each sporting activity multiplied by the corresponding MET value. Physical activity was then categorised into none, low (less than or equal to the sexspecific median; 9.6 MET-h/week for men and 7.3 MET-h/ week for women) and high (greater than the sex-specific median).

A standardised 3 day dietary record was employed for dietary assessment, as previously described [19]. Briefly, local dietitians instructed individuals on how to record all food and beverages consumed over 3 days (two workdays and a Sunday) with the help of standardised food portion sizes. The local dietitian reviewed each completed record with each individual. Then, with the use of a centrally prepared EURODIAB food list, the records were analysed to quantify the amounts of total energy, total protein (animal and vegetable protein), total fat (saturated and unsaturated fat), total carbohydrate, fibre and alcohol intake. Alcohol consumption was categorised into none, low (less than or equal to the sexspecific median; $12.7 \mathrm{~g} /$ day for men and $7.1 \mathrm{~g} /$ day for women) and high (greater than the sex-specific median). We did not quantify dietary salt intake based on dietary records as this is considered unreliable due to recall bias, variations of sodium content of common food items, lack of information on sodium added during cooking or at the table and imprecision with estimating portion size $[20,21]$.

Statistical analyses All statistical analyses were carried out using the Predictive Analytics SoftWare, version 18.0 (SPSS IBM Corporation, Armonk, NY, USA), unless specified otherwise. Variables with a skewed distribution (i.e. GFR, triacylglycerols) were $\log _{e}$ transformed prior to all analyses.

General characteristics were compared between categories of urinary sodium excretion with the use of ANOVA or $\chi^{2}$ tests for continuous or categorical data, respectively.

In all, 378 individuals ( $31 \%$ of the total population) had missing values for one or more of the covariables. The percentage of missing values per variable varied from $0.1 \%$ (physical activity) to $17 \%$ (dietary intake). We used multiple imputation chained equations to impute those missing values rather than perform complete case analyses in order to decrease bias and increase the power of the analyses [22]. With this procedure, the imputation model of a single missing variable used the information from all the other variables considered as predictors by appropriate regression models (i.e. linear or logistic if variable to be imputed was continuous or dichotomous, respectively). We generated five imputed datasets, which were used to fit the regression models of interest. The results reported were those retrieved from pooled analyses on all five imputed datasets.

We used logistic regression analyses to investigate the associations between dietary salt intake and potassium excretion on the one hand and the prevalence of microvascular complications on the other, after adjustment first for age and sex (model 1), then additionally for BMI, smoking, urinary potassium (in the case of sodium), urinary sodium (in the case of potassium) and use of antihypertensive medication (model 2 ), and further for physical activity and total energy, protein, saturated fat, fibre and alcohol intake (model 3). We investigated these associations both with dietary salt intake divided into categories of $7.5-10$ and $>10 \mathrm{~g} /$ day vs $<7.5 \mathrm{~g}$ /day, and with dietary salt intake as a continuous variable. We added quadratic terms of salt intake to our models to statistically examine potential non-linearity. To increase the power of our analyses, we present the analyses with salt intake as a continuous variable whenever no consistent non-linear associations between dietary salt intake and microvascular complications were found.

All regression analyses were conducted in the whole study population and also in the subgroup of individuals without prevalent CVD and/or antihypertensive medication, because individuals with prior CVD and/or known (treated) hypertension may have received dietary advice to reduce their salt intake, which may mask any associations. We additionally tested for interaction by variables that may modify dietary salt sensitivity at a given intake, i.e. urinary potassium excretion, kidney function and BMI, on the multiplicative scale by adding product terms between these variables and urinary sodium excretion to the fully adjusted models and on the additive scale by calculating the relative excess risk due to interaction (RERI) [23]. CIs of the RERI were estimated by using a bootstrap method with 10,000 bootstrap samples in $\mathrm{R}$ statistical software, version 2.15 .2 (http://www.r-project.org) [23]. We stratified our analyses whenever significant interactions were found.

We performed sensitivity analyses to investigate the robustness of significant associations between dietary salt intake and microvascular complications by excluding individuals with potential under or over urine collections. Under or over collections of $24 \mathrm{~h}$ urine samples were defined as the lower and upper $2.5 \%$ of the difference between the measured GFR ([urine creatinine] $* 24 \mathrm{~h}$ urine volume/[serum creatinine]) and estimated GFR (using the CKD-EPI equation). We performed these sensitivity analyses in a subgroup in which urine creatinine concentrations were available $(n=484)$ [24]. 


\section{Results}

The correlation between the two $24 \mathrm{~h}$ urine samples was $r=$ $0.60(p<0.001)$ for sodium excretion and $r=0.56(p<0.001)$ for potassium excretion, and the correlation between urinary sodium and potassium excretion was $r=0.44(p<0.001)$. The average $24 \mathrm{~h}$ urinary sodium excretion rate was $4.0 \mathrm{~g} / \mathrm{day}$, which roughly corresponds to a dietary salt intake of $9.9 \mathrm{~g} /$ day.
Table 1 shows the general characteristics of the 1,212 individuals of the EURODIAB study population at followup (1997) with available data on urinary sodium and potassium excretion. Data are presented for the total population $(n=$ $1,212)$ and stratified according to categories of dietary salt intake.

Individuals with higher salt intake were more often men and had on average higher values of BMI, urinary volume,

Table 1 General characteristics of the EURODIAB study

\begin{tabular}{|c|c|c|c|c|c|}
\hline & \multirow{2}{*}{$\begin{array}{l}\text { Total population } \\
(n=1,212)\end{array}$} & \multicolumn{4}{|c|}{ Dietary salt intake } \\
\hline & & $\begin{array}{l}<7.5 \text { g/day } \\
(n=352)\end{array}$ & $\begin{array}{l}7.5-10 \mathrm{~g} / \text { day } \\
(n=347)\end{array}$ & $\begin{array}{l}>10 \mathrm{~g} / \text { day } \\
(n=513)\end{array}$ & $p_{\text {trend }}$ \\
\hline Age (years) & $39.9 \pm 9.8$ & $39.6 \pm 9.4$ & $39.5 \pm 9.6$ & $40.4 \pm 10.2$ & 0.21 \\
\hline Male sex (\%) & 51 & 43 & 45 & 61 & $<0.001$ \\
\hline $\mathrm{BMI}\left(\mathrm{kg} / \mathrm{m}^{2}\right)$ & $24.7 \pm 3.3$ & $24.0 \pm 2.9$ & $24.7 \pm 3.5$ & $25.1 \pm 3.3$ & $<0.001$ \\
\hline $\mathrm{HbA}_{1 \mathrm{c}}(\%)(\mathrm{mmol} / \mathrm{mol})$ & $\begin{array}{l}8.4 \pm 1.5 \\
(68 \pm 16)\end{array}$ & $\begin{array}{l}8.6 \pm 1.5 \\
(70 \pm 16)\end{array}$ & $\begin{array}{l}8.3 \pm 1.4 \\
(67 \pm 15)\end{array}$ & $\begin{array}{l}8.4 \pm 1.5 \\
(68 \pm 16)\end{array}$ & 0.31 \\
\hline Duration of diabetes (years) & $21.8 \pm 9.3$ & $21.9 \pm 9.0$ & $21.7 \pm 9.7$ & $21.7 \pm 9.2$ & 0.78 \\
\hline Total cholesterol (mmol/1) & $5.3 \pm 1.1$ & $5.3 \pm 1.1$ & $5.2 \pm 1.0$ & $5.4 \pm 1.2$ & 0.37 \\
\hline LDL cholesterol (mmol/1) & $3.2 \pm 1.0$ & $3.2 \pm 0.9$ & $3.0 \pm 0.9$ & $3.3 \pm 1.1$ & 0.23 \\
\hline HDL cholesterol (mmol/1) & $1.6 \pm 0.4$ & $1.6 \pm 0.4$ & $1.6 \pm 0.5$ & $1.6 \pm 0.4$ & 0.21 \\
\hline Triacylglycerols (mmol/1) & $1.0(0.8-1.4)$ & $1.0(0.8-1.4)$ & $0.9(0.8-1.3)$ & $1.0(0.8-1.4)$ & 0.51 \\
\hline Smoking (never/ex/current) $(\%)$ & $42 / 29 / 29$ & $43 / 29 / 28$ & $46 / 27 / 27$ & $39 / 31 / 30$ & 0.14 \\
\hline Systolic BP (mmHg) & $121 \pm 19$ & $120 \pm 19$ & $122 \pm 19$ & $122 \pm 19$ & 0.25 \\
\hline Diastolic BP (mmHg) & $74 \pm 12$ & $73 \pm 12$ & $74 \pm 12$ & $75 \pm 12$ & 0.059 \\
\hline Use of antihypertensive medication (\%) & 25 & 27 & 22 & 25 & 0.57 \\
\hline Use of ACE inhibitors (\%) & 21 & 22 & 17 & 22 & 0.94 \\
\hline Use of diuretics $(\%)$ & 4 & 5 & 3 & 4 & 0.20 \\
\hline Estimated GFR (ml/min) & $102(90-112)$ & $102(86-111)$ & $103(90-111)$ & $103(92-113)$ & 0.049 \\
\hline Urinary volume (1) & $1.8 \pm 0.7$ & $1.6 \pm 0.6$ & $1.7 \pm 0.6$ & $2.1 \pm 0.7$ & $<0.001$ \\
\hline Urinary creatinine $(\mathrm{mmol})^{\mathrm{a}}$ & $11.7 \pm 3.9$ & $10.0 \pm 3.4$ & $11.3 \pm 3.6$ & $13.3 \pm 3.8$ & $<0.001$ \\
\hline CVD $(\%)$ & 13 & 13 & 12 & 13 & 0.66 \\
\hline Albuminuria (normo/micro/macro) (\%) & $71 / 17 / 12$ & $73 / 14 / 13$ & $76 / 15 / 9$ & $67 / 20 / 13$ & 0.11 \\
\hline Retinopathy (none/non-proliferative/proliferative) (\%) & $31 / 48 / 21$ & $31 / 47 / 22$ & $33 / 44 / 23$ & $29 / 52 / 19$ & 0.75 \\
\hline Urinary sodium excretion (g/day) & $3.96 \pm 1.60$ & $2.29 \pm 0.53$ & $3.49 \pm 0.28$ & $5.43 \pm 1.25$ & NA \\
\hline Urinary sodium excretion (mmol/day) & $172 \pm 69$ & $100 \pm 23$ & $152 \pm 12$ & $236 \pm 54$ & NA \\
\hline Urinary potassium excretion (g/day) & $2.91 \pm 1.09$ & $2.40 \pm 0.90$ & $2.80 \pm 0.95$ & $3.34 \pm 1.14$ & $<0.001$ \\
\hline Urinary potassium excretion (mmol/day) & $75 \pm 28$ & $62 \pm 23$ & $72 \pm 24$ & $86 \pm 29$ & $<0.001$ \\
\hline Physical activity $\left(0 / \leq\right.$ median $^{\mathrm{b}} />$ median $)(\%)$ & $60 / 20 / 19$ & $61 / 22 / 17$ & $57 / 24 / 19$ & $62 / 16 / 21$ & 0.70 \\
\hline Total energy intake (kJ/day) & $9856 \pm 2887$ & $9147 \pm 2620$ & $9590 \pm 2718$ & $10522 \pm 3030$ & $<0.001$ \\
\hline Protein intake (g/day) & $97.8 \pm 29.1$ & $90.5 \pm 27.1$ & $93.8 \pm 26.7$ & $105.6 \pm 30.2$ & $<0.001$ \\
\hline Alcohol intake $\left(0 / \leq\right.$ median $^{\mathrm{c}},>$ median $\left.[\%]\right)$ & $45 / 27 / 28$ & $42 / 27 / 31$ & $49 / 25 / 26$ & $44 / 29 / 27$ & 0.55 \\
\hline Saturated fat intake (g/day) & $35.8 \pm 15.3$ & $33.2 \pm 14.4$ & $35.1 \pm 14.2$ & $37.9 \pm 16.2$ & $<0.001$ \\
\hline Fibre intake (g/day) & $19.9 \pm 8.5$ & $18.1 \pm 7.2$ & $19.2 \pm 8.0$ & $21.5 \pm 9.4$ & $<0.001$ \\
\hline
\end{tabular}

Data are presented as means $\pm \mathrm{SD}$, medians (interquartile range) or percentages, as appropriate

${ }^{\text {a }}$ urinary creatinine was only available in $n=489$

${ }^{\mathrm{b}}$ sex-specific medians for physical activity were 9.6 MET-h/week for men and 7.3 MET-h/week for women

${ }^{\mathrm{c}}$ sex-specific medians for alcohol intake were $12.7 \mathrm{~g} /$ day for men and $7.1 \mathrm{~g} / \mathrm{day}$ for women 
urinary creatinine and potassium excretion, and higher total energy and protein intake (Table 1).

After adjustment for age and sex, we found no associations between dietary salt intake (per $1 \mathrm{~g} /$ day) and systolic BP $(-0.14 \mathrm{mmHg}[95 \% \mathrm{CI}-0.39,0.12])$ or diastolic BP $(0.02$ $[-95 \%$ CI $0.15,0.19])$.

Associations between dietary salt intake and microvascular complications After adjustment for age and sex, $>10 \mathrm{~g} /$ day salt intake, when compared with $<7.5 \mathrm{~g}$ /day salt intake, was positively associated with the prevalence of microalbuminuria (OR 1.46 [95\% CI 1.00, 2.13]). After full adjustment a similar association with microalbuminuria was found (OR 1.40 [95\% CI $0.92,2.15]$ ), although this was no longer significant (ESM Table 1). When individuals with CVD and/or those who used antihypertensive medication were excluded we found a similar positive, although non-significant, association between $>10 \mathrm{~g} /$ day salt intake and microalbuminuria (OR 1.26 [95\% CI $0.74,2.15])$ and macroalbuminuria (OR 1.34 [95\% CI $0.55,3.27]$ ) compared with $<7.5 \mathrm{~g}$ /day salt intake (ESM Table 2). We found no consistent associations between 7.5$10 \mathrm{~g} /$ day or $>10 \mathrm{~g} /$ day salt intake and non-proliferative or proliferative retinopathy, when compared with $<7.5 \mathrm{~g} /$ day salt intake either in the total population (ESM Table 1) or after exclusion of individuals with CVD and/or antihypertensive medication (ESM Table 2). In addition, we found no significant associations between the quadratic terms of salt intake and microvascular complications (all $p>0.46$ ). Taken together, these analyses provide no consistent evidence for nonlinear associations between salt intake and microvascular complications. We therefore present all further analyses per $1 \mathrm{~g} /$ day higher salt intake.

After adjustment for age and sex, $1 \mathrm{~g} /$ day higher dietary salt intake was positively associated with microalbuminuria (OR $1.06[95 \%$ CI 1.02, 1.10]) but not with macroalbuminuria (OR 1.00 [95\% CI 0.95, 1.04]), non-proliferative retinopathy (OR $1.02[95 \%$ CI $0.98,1.05])$ or proliferative retinopathy (OR 0.99 [95\% CI 0.94, 1.03]) (Table 2). After excluding individuals with CVD and/or antihypertensive medication $(n=418)$, we found a similar positive association with microalbuminuria (OR 1.05 [95\% CI 1.00, 1.11]) and also, although not significantly so, with macroalbuminuria (OR 1.04 [95\% CI $[0.96 ; 1.13]$ ), with no associations for nonproliferative retinopathy (OR 1.01 [95\% CI 0.97, 1.05]) or proliferative retinopathy (OR 1.02 [95\% CI 0.95, 1.09]) (Table 3). Essentially the same results were found in the fully adjusted models (Tables 2 and 3).

We found no consistent significant additive or multiplicative interactions between salt intake and urinary potassium excretion or kidney function in the associations with microvascular complications (data not shown). However, in the association between salt intake and microalbuminuria we did find an interaction with BMI ( $p$ for multiplicative interaction 0.050 and RERI $0.02[95 \% \mathrm{CI}-0.02,0.07)]$ such that the association was stronger in individuals with BMI $>25 \mathrm{~kg} / \mathrm{m}^{2}$ (OR 1.11 [95\% CI 1.04, 1.18]) than in those with BMI $<25 \mathrm{~kg} / \mathrm{m}^{2}$ (OR 1.03 [95\% CI 0.97, 1.09]).

Associations between urinary potassium excretion and microvascular complications After adjustment for age and sex we found no significant associations between urinary potassium excretion (in g/day) and microalbuminuria (OR 1.09 [95\% CI $0.95,1.25]$ ), macroalbuminuria (OR 0.98 [95\% CI 0.83, 1.16]) and non-proliferative (OR 1.12 [95\% CI 0.98, 1.27]) or proliferative (OR 0.87 [95\% CI 0.73, 1.04]) retinopathy (Table 4). Similarly, no significant associations were found after full adjustment (Table 4) or when individuals with CVD and/or those who used antihypertensive medication were excluded (Table 5). In addition, we found no consistent significant additive or multiplicative interactions of urinary potassium excretion with urinary sodium excretion, kidney function or BMI (data not shown).

Additional analyses Use of salt intake $<5.0 \mathrm{~g} /$ day $(n=85)$ instead of $<7.5 \mathrm{~g} /$ day $(n=352)$ as a reference category did not materially change our results (data not shown).

Table 2 Continuous associations between dietary salt intake and prevalent albuminuria and retinopathy

\begin{tabular}{|c|c|c|c|c|c|c|c|c|c|c|c|c|}
\hline \multirow[b]{2}{*}{ Model } & \multicolumn{3}{|c|}{$\begin{array}{l}\text { Microalbuminuria } \\
(205 / 1,068)\end{array}$} & \multicolumn{3}{|c|}{$\begin{array}{l}\text { Macroalbuminuria } \\
(143 / 1,006)\end{array}$} & \multicolumn{3}{|c|}{$\begin{array}{l}\text { Non-proliferative retinopathy } \\
(507 / 833)\end{array}$} & \multicolumn{3}{|c|}{$\begin{array}{l}\text { Proliferative retinopathy } \\
(224 / 550)\end{array}$} \\
\hline & OR & $95 \%$ CI & $p$ & OR & $95 \% \mathrm{CI}$ & $p$ & OR & $95 \% \mathrm{CI}$ & $p$ & OR & $95 \%$ CI & $p$ \\
\hline 1 & 1.06 & $1.02,1.10$ & 0.003 & 1.00 & $0.95,1.04$ & 0.88 & 1.02 & $0.98,1.05$ & 0.34 & 0.99 & $0.94,1.03$ & 0.53 \\
\hline 2 & 1.06 & $1.01,1.10$ & 0.011 & 1.00 & $0.94,1.06$ & 0.95 & 1.00 & $0.96,1.04$ & 0.94 & 1.02 & $0.96,1.08$ & 0.64 \\
\hline 3 & 1.06 & $1.01,1.10$ & 0.013 & 0.99 & $0.94,1.05$ & 0.82 & 1.00 & $0.96,1.04$ & 0.84 & 1.02 & $0.95,1.08$ & 0.65 \\
\hline
\end{tabular}

OR indicates the odds of prevalent albuminuria or retinopathy per g/day salt intake

Model 1: adjusted for age and sex

Model 2: model 1 + BMI, smoking (never/ex/current), urinary potassium excretion and use of antihypertensive medication

Model 3: model $2+$ physical activity $(0 / \leq$ sex-specific median/>sex-specific median $)$, total energy intake, protein intake, saturated fat intake, fibre intake, alcohol intake $(0 / \leq$ sex-specific median/>sex-specific median) 
Table 3 Continuous associations between dietary salt intake and prevalent albuminuria and retinopathy in individuals without CVD who did not use antihypertensive medication

\begin{tabular}{|c|c|c|c|c|c|c|c|c|c|c|c|c|}
\hline \multirow[b]{2}{*}{ Model } & \multicolumn{3}{|c|}{$\begin{array}{l}\text { Microalbuminuria } \\
(116 / 794)\end{array}$} & \multicolumn{3}{|c|}{$\begin{array}{l}\text { Macroalbuminuria } \\
(41 / 719)\end{array}$} & \multicolumn{3}{|c|}{$\begin{array}{l}\text { Non-proliferative retinopathy } \\
(367 / 642)\end{array}$} & \multicolumn{3}{|c|}{$\begin{array}{l}\text { Proliferative retinopathy } \\
(92 / 367)\end{array}$} \\
\hline & OR & $95 \% \mathrm{CI}$ & $p$ & OR & $95 \% \mathrm{CI}$ & $p$ & OR & $95 \% \mathrm{CI}$ & $p$ & OR & $95 \% \mathrm{CI}$ & $p$ \\
\hline 1 & 1.05 & $1.00,1.11$ & 0.049 & 1.04 & $0.96,1.13$ & 0.36 & 1.01 & $0.97,1.05$ & 0.66 & 1.02 & $0.95,1.09$ & 0.63 \\
\hline 2 & 1.04 & $0.98,1.10$ & 0.17 & 1.05 & $0.96,1.15$ & 0.30 & 0.98 & $0.94,1.03$ & 0.44 & 1.02 & $0.95,1.10$ & 0.54 \\
\hline 3 & 1.04 & $0.99,1.10$ & 0.14 & 1.05 & $0.96,1.16$ & 0.30 & 0.98 & $0.93,1.02$ & 0.32 & 1.02 & $0.95,1.10$ & 0.59 \\
\hline
\end{tabular}

OR indicates the odds of prevalent albuminuria or retinopathy per g/day salt intake

Model 1: adjusted for age and sex

Model 2: model $1+$ BMI, smoking (never/ex/current) and urinary potassium excretion

Model 3: model $2+$ physical activity $(0 / \leq$ sex-specific median/ $>$ sex-specific median $)$, total energy intake, protein intake, saturated fat intake, fibre intake, alcohol intake $(0 / \leq$ sex-specific median $/>$ sex-specific median $)$

Sensitivity analyses In the subgroup of 484 individuals who had urine creatinine values available we found a positive association between dietary salt intake and microalbuminuria (OR 1.12 [95\% CI 1.04, 1.22] after full adjustment), which was similar after exclusion of individuals with potential under or over $24 \mathrm{~h}$ urine collections ( $n=24$; OR 1.12 [95\% CI 1.03 , $1.22])$.

Complete case analyses showed similar results to the multiple imputation analyses as presented throughout the manuscript.

\section{Discussion}

The present study showed that in individuals with type 1 diabetes, higher dietary salt intake, as estimated by $24 \mathrm{~h}$ urinary sodium excretion, was associated with a higher prevalence of microalbuminuria, an association that was more pronounced in overweight individuals, but not with macroalbuminuria or retinopathy. In addition, no significant associations were found between urinary potassium excretion and the prevalence of microvascular complications.
Previous studies on the cross-sectional association between dietary salt intake and microalbuminuria in the general population have been conflicting, that is both no $[4,8]$ and positive $[5-7,9]$ associations have been described. Interestingly, these positive associations were more pronounced in individuals with a higher BMI [5] or were found only in obese individuals [7]. The present results of a more pronounced positive association between dietary salt intake and microalbuminuria in individuals with type 1 diabetes and a BMI $>25 \mathrm{~kg} / \mathrm{m}^{2}$ support previous findings $[5,6]$. Overweight and obesity have been associated with both salt sensitivity [7,25] and increased glomerular filtration fraction and GFR [26], which might explain the stronger associations between salt intake and microalbuminuria.

In contrast, two studies in individuals with type 2 [10] or type 1 diabetes [11] found inverse (or J-shaped) associations between dietary salt intake and prevalent microalbuminuria [10] or incident end-stage renal disease [11]. These findings are in line with several other recent studies that showed Jshaped associations between dietary salt intake and incident CVD and mortality in general [27], as well as in high-risk populations [28] and in individuals with type 1 [11] and type 2

Table 4 Continuous associations between urinary potassium excretion and prevalent albuminuria and retinopathy

\begin{tabular}{|c|c|c|c|c|c|c|c|c|c|c|c|c|}
\hline \multirow[b]{2}{*}{ Model } & \multicolumn{3}{|c|}{$\begin{array}{l}\text { Microalbuminuria } \\
(205 / 1,068)\end{array}$} & \multicolumn{3}{|c|}{$\begin{array}{l}\text { Macroalbuminuria } \\
(143 / 1,006)\end{array}$} & \multicolumn{3}{|c|}{$\begin{array}{l}\text { Non-proliferative retinopathy } \\
(507 / 833)\end{array}$} & \multicolumn{3}{|c|}{$\begin{array}{l}\text { Proliferative retinopathy } \\
(224 / 550)\end{array}$} \\
\hline & OR & $95 \% \mathrm{CI}$ & $p$ & OR & $95 \%$ CI & $p$ & OR & $95 \% \mathrm{CI}$ & $p$ & OR & $95 \% \mathrm{CI}$ & $p$ \\
\hline 1 & 1.09 & $0.95,1.25$ & 0.20 & 0.98 & $0.83,1.16$ & 0.79 & 1.12 & $0.98,1.27$ & 0.10 & 0.87 & $0.73,1.04$ & 0.13 \\
\hline 2 & 1.03 & $0.88,1.20$ & 0.76 & 1.04 & $0.85,1.28$ & 0.71 & 1.10 & $0.94,1.28$ & 0.24 & 0.84 & $0.67,1.05$ & 0.12 \\
\hline 3 & 1.03 & $0.88,1.22$ & 0.68 & 1.07 & $0.86,1.32$ & 0.57 & 1.11 & $0.95,1.30$ & 0.20 & 0.88 & $0.69,1.12$ & 0.29 \\
\hline
\end{tabular}

OR indicates the odds of prevalent albuminuria or retinopathy per $\mathrm{g}$ /day potassium excretion

Model 1: adjusted for age and sex

Model 2: model $1+$ BMI, smoking (never/ex/current), urinary sodium excretion and use of antihypertensive medication

Model 3: model $2+$ physical activity $(0 / \leq$ sex-specific median $>$ sex-specific median $)$, total energy intake, protein intake, saturated fat intake, fibre intake, alcohol intake $(0 / \leq$ sex-specific median/>sex-specific median) 
Table 5 Continuous associations between urinary potassium excretion and prevalent albuminuria and retinopathy in individuals without CVD who did not use antihypertensive medication

\begin{tabular}{|c|c|c|c|c|c|c|c|c|c|c|c|c|}
\hline \multirow[b]{2}{*}{ Model } & \multicolumn{3}{|c|}{$\begin{array}{l}\text { Microalbuminuria } \\
(114 / 779)\end{array}$} & \multicolumn{3}{|c|}{$\begin{array}{l}\text { Macroalbuminuria } \\
(40 / 705)\end{array}$} & \multicolumn{3}{|c|}{$\begin{array}{l}\text { Non-proliferative retinopathy } \\
(360 / 633)\end{array}$} & \multicolumn{3}{|c|}{$\begin{array}{l}\text { Proliferative retinopathy } \\
(92 / 365)\end{array}$} \\
\hline & OR & $95 \% \mathrm{CI}$ & $p$ & OR & $95 \% \mathrm{CI}$ & $p$ & OR & $95 \% \mathrm{CI}$ & $p$ & OR & $95 \% \mathrm{CI}$ & $p$ \\
\hline 1 & 1.12 & $0.95,1.33$ & 0.18 & 0.92 & $0.68,1.25$ & 0.60 & 1.15 & $0.99,1.33$ & 0.074 & 0.88 & $0.69,1.14$ & 0.34 \\
\hline 2 & 1.06 & $0.88,1.28$ & 0.55 & 0.85 & $0.60,1.20$ & 0.35 & 1.15 & $0.97,1.36$ & 0.10 & 0.84 & $0.63,1.11$ & 0.21 \\
\hline 3 & 1.07 & $0.88,1.30$ & 0.52 & 0.82 & $0.57,1.17$ & 0.28 & 1.16 & $0.98,1.39$ & 0.090 & 0.91 & $0.68,1.22$ & 0.52 \\
\hline
\end{tabular}

OR indicates the odds of prevalent albuminuria or retinopathy per g/day potassium excretion

Model 1: adjusted for age and sex

Model 2: model $1+$ BMI, smoking (never/ex/current) and urinary sodium excretion

Model 3: model $2+$ physical activity $(0 / \leq$ sex-specific median/>sex-specific median), total energy intake, protein intake, saturated fat intake, fibre intake, alcohol intake $(0 / \leq$ sex-specific median/>sex-specific median)

diabetes [29]. However, several methodological aspects of these studies have been criticised, such as the use of a single $24 \mathrm{~h}$ urine sample, which may poorly represent usual sodium intake at the individual level [30,31], potential problematic completeness of urine collection [30] and unmeasured and residual confounding [32]. Furthermore, the low salt-intake groups may have included persons who followed a low salt diet, which may have been recommended to those with hypertension or otherwise increased CVD risk, which could have biased the findings [31]. In addition, in the present study we found no evidence for such non-linear associations between dietary salt intake and microvascular complications. Whether or not low dietary salt intake is associated with increased cardiovascular risk and/or microvascular complications thus remains to be established.

Potassium has been shown to exert an inhibitory effect on sodium sensitivity [13], and the association between sodium intake and microvascular complications may thus be modified by potassium intake. In addition, high sodium intake in combination with low potassium intake results in further excess of sodium in the body and higher BP [13]. However, we did not find evidence to support an effect-modifying role of potassium excretion in the association between sodium excretion and microvascular complications nor that of an (inverse) association between potassium excretion and microvascular complications in individuals with type 1 diabetes. In addition, although individuals with decreased kidney function are more commonly BP salt-sensitive, and kidney function may thus modify the association between dietary salt intake and microvascular complications, we found no evidence to support this contention. However, we may have lacked power to show this association, and larger and prospective studies are needed to fully address these issues.

Increasing dietary salt intake increases BP in salt-sensitive individuals both with [33] and without [34] type 1 diabetes. In individuals with type 1 diabetes, elevated BP has been associated with the development of microalbuminuria [35], which may result from an increase in the ratio of GFR to the renal plasma flow, i.e. an increased glomerular filtration fraction, with a resultant increase in proteinuria [34]. In the current study, however, higher dietary salt intake was not associated with elevated BP. Individuals with elevated BP may have changed their dietary habits to reduce salt intake, which may have masked these cross-sectional associations. However, the association between dietary salt intake and microalbuminuria may also be mediated by processes other than increases in BP. High salt intake may activate the local renin-angiotensinaldosterone system in the vessels as well as in the kidney [36], stimulating the secretion of aldosterone, and this may have detrimental effects on endothelium-dependent dilation [37] as it may stimulate central sympathetic outflow creating a hyperadrenergic state [38] and the formation of reactive oxygen species suppressing nitric oxide availability [39]. Similar effects of aldosterone may be exerted via increased signalling of the mineralocorticoid receptor resulting from or in combination with high salt intake [40]. However, we cannot draw any conclusions of a cause-and-effect relationship between salt intake and microalbuminuria based on the current crosssectional study.

Although the current study is the largest study investigating the association between dietary salt intake and (early) microvascular complications in individuals with type 1 diabetes so far, a limitation that needs to be addressed is the cross-sectional design. We cannot exclude that individuals with prior CVD and/or known (treated) hypertension have received dietary advice to reduce their salt intake, which may have masked the associations. We have therefore performed all analyses not only in the total population but also in the individuals without prevalent CVD and/or antihypertensive medication. However, the analyses in this subpopulation might have been underpowered due to low numbers of microvascular complication cases in particular of macroalbuminuria. Further investigation in larger, prospective studies is warranted to address the role of dietary salt intake in the development of microvascular complications in type 1 diabetes. 
In conclusion, in individuals with type 1 diabetes, high dietary salt intake may be a risk factor for microalbuminuria, particularly in overweight individuals, and nutritional advice regarding salt intake may thus be important in preventing or slowing the rate of development of microvascular disease in individuals with type 1 diabetes. Further investigation in prospective studies is warranted to fully address the role of dietary salt intake in the development of microvascular complications in type 1 diabetes.

Acknowledgements A complete list of members of the EURODIAB Prospective Complications Study Group is provided in the ESM.

Funding The research is funded by TI Food and Nutrition, a publicprivate partnership on pre-competitive research in food and nutrition. The funders had no role in study design, data collection and analysis, decision to publish, or preparation of the manuscript.

The EURODIAB study data collection was supported by grants from the Wellcome Trust, European Community and Diabetes UK to NC and JHF.

SSSM was supported by the Royal Netherlands Academy of Arts and Sciences.

Duality of interest The authors declare that there is no duality of interest associated with this manuscript.

Contribution statement LE contributed to analysis and interpretation of data and wrote the manuscript. SSSM and JMG contributed to analysis and interpretation of data and reviewed/edited the manuscript. MT contributed to acquisition of data and reviewed/edited the manuscript. NC and JHF contributed to conception and design of the study and acquisition of data and reviewed/edited the manuscript. CGS contributed to acquisition of data and reviewed/edited the manuscript. CDAS contributed to analysis and interpretation of data and reviewed/edited the manuscript. All authors approved the final version of the manuscript. CGS and CDAS are the guarantors of this work.

Open Access This article is distributed under the terms of the Creative Commons Attribution License which permits any use, distribution, and reproduction in any medium, provided the original author(s) and the source are credited.

\section{References}

1. Bantle JP, Wylie-Rosett J, Albright AL et al (2008) Nutrition recommendations and interventions for diabetes: a position statement of the American Diabetes Association. Diabetes Care 31(Suppl 1):S61-S78

2. Mann JI, de Leeuw I, Hermansen K et al (2004) Evidence-based nutritional approaches to the treatment and prevention of diabetes mellitus. Nutr Metab Cardiovasc Dis 14:373-394

3. Kotchen TA, Cowley AW Jr, Frohlich ED (2013) Salt in health and disease - a delicate balance. N Engl J Med 368:1229-1237

4. Daviglus ML, Greenland P, Stamler J et al (2005) Relation of nutrient intake to microalbuminuria in nondiabetic middle-aged men and women: International Population Study on Macronutrients and Blood Pressure (INTERMAP). Am J Kidney Dis 45:256-266

5. Verhave JC, Hillege HL, Burgerhof JG et al (2004) Sodium intake affects urinary albumin excretion especially in overweight subjects. J Intern Med 256:324-330

6. du Cailar G, Ribstein J, Mimran A (2002) Dietary sodium and target organ damage in essential hypertension. Am J Hypertens 15:222-229
7. Aaron KJ, Campbell RC, Judd SE, Sanders PW, Muntner P (2011) Association of dietary sodium and potassium intakes with albuminuria in normal-weight, overweight, and obese participants in the Reasons for Geographic and Racial Differences in Stroke (REGARDS) Study. Am J Clin Nutr 94:1071-1078

8. Lin J, Hu FB, Curhan GC (2010) Associations of diet with albuminuria and kidney function decline. Clin J Am Soc Nephrol 5: 836-843

9. Fox CS, Larson MG, Hwang SJ et al (2006) Cross-sectional relations of serum aldosterone and urine sodium excretion to urinary albumin excretion in a community-based sample. Kidney Int 69:2064-2069

10. Sakabe K, Fukui M, Ushigome E et al (2012) Low daily salt intake is correlated with albuminuria in patients with type 2 diabetes. Hypertens Res 35:1176-1179

11. Thomas MC, Moran J, Forsblom C et al (2011) The association between dietary sodium intake, ESRD, and all-cause mortality in patients with type 1 diabetes. Diabetes Care 34:861-866

12. Roy MS, Janal MN (2010) High caloric and sodium intakes as risk factors for progression of retinopathy in type 1 diabetes mellitus. Arch Ophthalmol 128:33-39

13. Adrogue HJ, Madias NE (2007) Sodium and potassium in the pathogenesis of hypertension. N Engl J Med 356:1966-1978

14. Koivisto VA, Stevens LK, Mattock M et al (1996) Cardiovascular disease and its risk factors in IDDM in Europe. EURODIAB IDDM Complications Study Group. Diabetes Care 19:689-697

15. Stephenson F, Fuller JH, on behalf of the EURODIAB IDDM Complications Study Group (1994) Microvascular and acute complications in IDDM patients: the EURODIAB IDDM Complications Study. Diabetologia 37:278-285

16. Chaturvedi N, Bandinelli S, Mangili R, Penno G, Rottiers RE, Fuller JH (2001) Microalbuminuria in type 1 diabetes: rates, risk factors and glycemic threshold. Kidney Int 60:219-227

17. Levey AS, Stevens LA, Schmid CH et al (2009) A new equation to estimate glomerular filtration rate. Ann Intern Med 150:604-612

18. Aldington SJ, Kohner EM, Meuer S, Klein R, Sjolie AK (1995) Methodology for retinal photography and assessment of diabetic retinopathy: the EURODIAB IDDM complications study. Diabetologia 38:437-444

19. Toeller M, Klischan A, Heitkamp G et al (1996) Nutritional intake of 2868 IDDM patients from 30 centres in Europe. EURODIAB IDDM Complications Study Group. Diabetologia 39:929-939

20. Brown IJ, Tzoulaki I, Candeias V, Elliott P (2009) Salt intakes around the world: implications for public health. Int J Epidemiol 38:791-813

21. Hunter D (1998) Biochemical indicators of dietary intake. In: Willet W (ed) Nutritional epidemiology. Oxford University Press, Oxford, pp 174-243

22. Sterne JA, White IR, Carlin JB et al (2009) Multiple imputation for missing data in epidemiological and clinical research: potential and pitfalls. BMJ 338:b2393

23. Knol MJ, van der Tweel I, Grobbee DE, Numans ME, Geerlings MI (2007) Estimating interaction on an additive scale between continuous determinants in a logistic regression model. Int J Epidemiol 36: $1111-1118$

24. Chaturvedi N, Schalkwijk CG, Abrahamian H, Fuller JH, Stehouwer CD (2002) Circulating and urinary transforming growth factor beta1, Amadori albumin, and complications of type 1 diabetes: the EURODIAB prospective complications study. Diabetes Care 25: 2320-2327

25. Rocchini AP, Key J, Bondie D et al (1989) The effect of weight loss on the sensitivity of blood pressure to sodium in obese adolescents. N Engl J Med 321:580-585

26. Ribstein J, du Cailar G, Mimran A (1995) Combined renal effects of overweight and hypertension. Hypertension 26:610-615

27. Stolarz-Skrzypek K, Kuznetsova T, Thijs L et al (2011) Fatal and nonfatal outcomes, incidence of hypertension, and blood pressure 
changes in relation to urinary sodium excretion. JAMA 305: $1777-1785$

28. O'Donnell MJ, Yusuf S, Mente A et al (2011) Urinary sodium and potassium excretion and risk of cardiovascular events. JAMA 306: 2229-2238

29. Ekinci EI, Clarke S, Thomas MC et al (2011) Dietary salt intake and mortality in patients with type 2 diabetes. Diabetes Care 34:703-709

30. Labarthe DR, Briss PA (2011) Urinary sodium excretion and cardiovascular disease mortality. JAMA 306:1084-1085, author reply 1086-1087

31. Cook NR, Appel LJ, Whelton PK (2014) Lower levels of sodium intake and reduced cardiovascular risk. Circulation 129:981-989

32. Lambers Heerspink HJ, Kwakernaak A, de Zeeuw D, Navis G (2011) Comment on: Ekinci et al. Dietary salt intake and mortality in patients with type 2 diabetes. Diabetes Care 34:703-709, Diabetes Care 34: e124; author reply e125

33. Lambert J, Pijpers R, van Ittersum FJ et al (1997) Sodium, blood pressure, and arterial distensibility in insulin-dependent diabetes mellitus. Hypertension 30:1162-1168
34. Weir MR, Dengel DR, Behrens MT, Goldberg AP (1995) Saltinduced increases in systolic blood pressure affect renal hemodynamics and proteinuria. Hypertension 25:1339-1344

35. Marcovecchio ML, Dalton RN, Schwarze CP et al (2009) Ambulatory blood pressure measurements are related to albumin excretion and are predictive for risk of microalbuminuria in young people with type 1 diabetes. Diabetologia 52:1173-1181

36. Boddi M, Poggesi L, Coppo M et al (1998) Human vascular reninangiotensin system and its functional changes in relation to different sodium intakes. Hypertension 31:836-842

37. Stier CT (2013) Vascular effects of high-salt intake. J Hypertens 31: $472-473$

38. Gavras I, Gavras H (2012) 'Volume-expanded' hypertension: the effect of fluid overload and the role of the sympathetic nervous system in salt-dependent hypertension. J Hypertens 30:655-659

39. Lenda DM, Sauls BA, Boegehold MA (2000) Reactive oxygen species may contribute to reduced endothelium-dependent dilation in rats fed high salt. Am J Physiol Heart Circ Physiol 279:H7-H14

40. Lastra G, Dhuper S, Johnson MS, Sowers JR (2010) Salt, aldosterone, and insulin resistance: impact on the cardiovascular system. Nat Rev Cardiol 7:577-584 